\title{
When to Adjust Alpha During Multiple Testing: A Consideration of Disjunction, Conjunction, and Individual Testing
}

Mark Rubin ${ }^{1,2}$

${ }^{1}$ School of Psychology, Behavioural Sciences Building, The University of Newcastle

${ }^{2}$ The University of Newcastle

July 7, 2021

\section{Hosted file}

Rubin (2021) When to Adjust Alpha.pdf available at https://authorea.com/users/369566/ articles/529329-when-to-adjust-alpha-during-multiple-testing-a-consideration-ofdisjunction-conjunction-and-individual-testing 